\title{
Blockade of IL-33 release and suppression of type 2 innate lymphoid cell responses by helminth secreted products in airway allergy
}

\author{
HJ McSorley ${ }^{1}$, NF Blair ${ }^{1}$, KA Smith ${ }^{1}$, ANJ McKenzie ${ }^{2}$ and RM Maizels ${ }^{1}$
}

Helminth parasites such as the nematode Heligmosomoides polygyrus strongly inhibit T helper type 2 (Th2) allergy, as well as colitis and autoimmunity. Here, we show that the soluble excretory/secretory products of $H$. polygyrus (HES) potently suppress inflammation induced by allergens from the common fungus Alternaria alternata. Alternaria extract, when administered to mice intranasally with ovalbumin (OVA) protein, induces a rapid (1-48h) innate response while also priming an OVA-specific Th2 response that can be evoked 14 days later by intranasal administration of OVA alone. In this model, HES coadministration with Alternaria/OVA suppressed early IL-33 release, innate lymphoid cell (ILC) production of IL-4, IL-5, and IL-13, and localized eosinophilia. Upon OVA challenge, type 2 ILC (ILC2)/Th2 cytokine production and eosinophilia were diminished in HES-treated mice. HES administration $6 \mathrm{~h}$ before Alternaria blocked the allergic response, and its suppressive activity was abolished by heat treatment. Administration of recombinant IL-33 at sensitization with Alternaria/OVA/HES abrogated HES suppression of OVA-specific responses at challenge, indicating that suppression of early Alternaria-induced IL-33 release could be central to the anti-allergic effects of HES. Thus, this helminth parasite targets IL-33 production as part of its armory of suppressive effects, forestalling the development of the type 2 immune response to infection and allergic sensitization.

\section{INTRODUCTION}

The prevalence of allergic asthma has increased dramatically in developed countries over the last century, ${ }^{1}$ while over the same period the incidence of infections, especially with parasites, has sharply decreased. This has led to the hypothesis that the immune system is modulated in the presence of parasitic infections, and in their absence is prone to hyperactivity leading to immune-mediated diseases such as autoimmunity, inflammatory bowel disease, and allergy. ${ }^{2-4}$

Asthma is a multifactorial condition, characterized by airway obstruction, hyperactivity of the airways to stimuli, and fibrosis of the lungs. ${ }^{5}$ Most asthmatic individuals are characterized by a Thelper type 2 (Th2) response to allergens, with increased type 2 cytokines and eosinophilia in the lungs. Recently, the critical roles of both the airway epithelium, ${ }^{6}$ and newly described type 2 innate lymphoid cells (ILC2s) $)^{7-11}$ in the initiation and maintenance of asthma have been established. Thus, asthmatic inflammation develops through the concerted action of innate and adaptive immunity, and it is not yet known at what level helminth infection could act to suppress pathology.

Many asthmatic individuals are allergic to fungal molds, and the presence of fungi such as Alternaria in the household during early life predicts the development of asthma in later life. ${ }^{12} \mathrm{High}$ atmospheric concentrations of fungal spores (for instance during thunderstorms) also correlates with increased hospital admissions due to asthma exacerbations. ${ }^{13}$ Thus, fungal molds may be important both as initiators and as targets of allergic responses. $^{14}$

Alternaria extract is known to provoke allergic immune responses in mice, both in chronic Th2-mediated ${ }^{15,16}$ and in acute $\mathrm{T}$ cell-independent administration regimes. ${ }^{7,17-19}$ Thus it is an ideal setting in which to examine the relative roles of innate and adaptive type 2 responses during asthmatic pathology, and the effect of helminths and their products on these responses.

${ }^{1}$ Institute of Immunology and Infection Research, School of Biological Sciences, University of Edinburgh, Edinburgh, UK and ${ }^{2}$ MRC Laboratory of Molecular Biology, Cambridge, UK. Correspondence: RM Maizels (rick.maizels@ed.ac.uk) 
The development of lung eosinophilia to Alternaria extract in the early ( $<3$ days post administration) phase can be attributed to Alternaria-induced ILC2 activation and IL-5 and IL-13 production. ${ }^{7}$ ILCs, a non-B, non-T lymphocyte subset that expresses ICOS, CD44, CD25, and ST2 (the IL-33 receptor), respond to the alarmin cytokines IL-25 or IL-33 by producing large amounts of IL-5 and IL-13, are required for resistance to some parasites, ${ }^{20}$ and are instrumental for allergic responses in the lung. ${ }^{7-11}$ After Alternaria administration, both early ILC2 responses and eosinophilia have been shown to be critically dependent on IL-33 signaling, and were abrogated or ablated in IL-33-, ST2- (IL-33 receptor) or MyD88- (the IL-33-receptor signaling adaptor) deficient mice. ${ }^{7,17,21}$ Critically, these early responses are unchanged in recombinase-activating gene (RAG)-deficient mice and are therefore independent of the adaptive immune system. ${ }^{7,17}$

Heligmosomoides polygyrus is a natural parasite of wild mice, which is used as a laboratory model of chronic intestinal helminth infection. ${ }^{22} H$. polygyrus infection has multiple immunomodulatory effects including induction of regulatory $\mathrm{T}$ cells, ${ }^{23,24}$ regulatory B cells, ${ }^{25}$ and suppressive or suppressed dendritic cells. ${ }^{26-28}$ Infection also suppresses inflammatory responses in models of asthma, food allergy, diabetes, and colitis. ${ }^{4}$ Many of the suppressive effects of infection can be attributed to $H$. polygyrus excretory/secretory (HES) products, including Treg induction ${ }^{29}$ and dendritic cell suppression. ${ }^{26,30}$ Our aim is to identify suppressive molecules in HES with a view to develop these as novel therapeutic agents for human disease.

Recently, we described suppression of allergic airway responses in an alum adjuvant-dependent model of asthma by coadministration of HES. ${ }^{31}$ Alum-mediated sensitization is effected by the intraperitoneal route, and while this stimulates a strong pro-allergic Th2 response, initiating events may not well represent those at the airway epithelium. In particular, early lung alarmin responses are not induced during intraperitoneal alum administration, and ovalbumin (OVA)-Alum model responses (unlike those induced by Alternaria) are intact in MyD88-deficient mice, which lack receptor signaling from IL-1-family cytokines such as IL-33. ${ }^{32}$ In studying interactions between the innate and adaptive compartments, we therefore decided to examine a protocol in which airway inflammation is dependent on sensitization directly within the airways, using the clinically relevant Alternaria allergen and the model T-cell antigen OVA. As presented below, the HES products of $H$. polygyrus proved to be highly efficacious at suppressing the allergic response evoked in the airways.

\section{RESULTS}

HES suppresses inflammation and pathology in a mouse model of asthma

In studying how helminth parasites may modulate allergic responses, we previously reported that $H$. polygyrus infection, ${ }^{33}$ or the administration of secreted products from cultured parasites $\left(\mathrm{HES}^{31}\right)$ is able to suppress the expression of airway allergic inflammation in mice primed with allergens in alum adjuvant by the intraperitoneal route. Because this mode of sensitization is not physiologically related to the development of human asthma, we tested the ability of HES to inhibit allergy following airway sensitization, in a model of asthma similar to that described by Kobayashi et al. ${ }^{15}$

Mice were sensitized by intranasal administration of OVA protein with extract of the fungal organism Alternaria alternata, and the OVA-specific response was measured following the intranasal delivery of OVA protein alone 14 days later (Figure 1a). OVA challenge elicited a substantial eosinophilic infiltrate in the bronchoalveolar lavage (BAL) and lung tissue of mice which had been primed with OVA in the presence of Alternaria (Figure 1b,c; Supplementary Figure 1 online), while little change in neutrophils was observed (Figure 1d). No inflammation was seen in mice primed with soluble OVA alone, and only slight infiltration in animals receiving a phosphate-buffered saline (PBS) sham airway challenge (Figure 1e).

When HES was coadministered with the sensitizing dose, however, a striking reduction in inflammation was seen (Figure 1b,c,e; Supplementary Figure 1), with eosinophils reduced to levels of unchallenged mice. The suppressive effect of HES was ablated by heating to $95^{\circ} \mathrm{C}$ for $20 \mathrm{~min}$ before administration (Figure 1f), implying that this activity is dependent on native protein conformation, and is in contrast to the heat-stable suppressive effects of HES when administered at sensitization in the OVA-Alum model of asthma. ${ }^{31}$ Notably, HES is known to contain a heat-labile molecule with the ability to signal through the mammalian TGF- $\beta$ receptor. ${ }^{29}$ To investigate the role of the TGF- $\beta$ pathway, we tested the effect of administering an amount of recombinant TGF- $\beta$ which equated to the activity within HES. At the same time, we also tested Bovine Serum Albumin (BSA) as an unrelated protein to examine whether any form of antigen competition was reducing the allergic response to OVA. In neither case could the suppressive effect of HES be recapitulated (Figure 1g).

HES suppresses both innate and adaptive type 2 immunity The allergic response in OVA-Alternaria-primed mice displayed all the canonical features of type 2 immune responsiveness. Thus, the type 2 cytokines IL- 4 and IL- 5 were significantly upregulated in BAL supernatants from allergic mice, along with a trend for increased IL-13 (Figure 2a). In mice receiving HES at priming, these cytokine responses were suppressed without any evident switch to IFN$\gamma$ or IL-17A (Figure 2a). BAL fluids also contained elevated levels of the type 2 myeloid cell response markers RELM- $\alpha$ and $\mathrm{Ym} 1,{ }^{34}$ which were again suppressed by HES coadministration, although only significantly so in the case of RELM- $\alpha$ (Figure 2b).

Within the lungs of sensitized mice, the dominant Th2 response was reflected by enhanced ex vivo intracellular staining of lymphocytes for IL-4, IL- 5 , and IL- 13 by CD4 ${ }^{+}$ $\mathrm{T}$ cells, alongside a small increase in IFN- $\gamma$ and a trend for increased IL-17A production. Th2 cytokine expression was diminished in recipients of HES (Figure 2c), although to a 
a

Day 0
$\begin{gathered}\text { OVA IN } \\ \text { Alternaria } \\ \pm \text { HES }\end{gathered}$

b

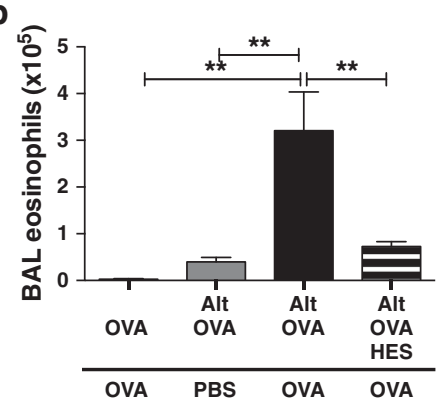

C

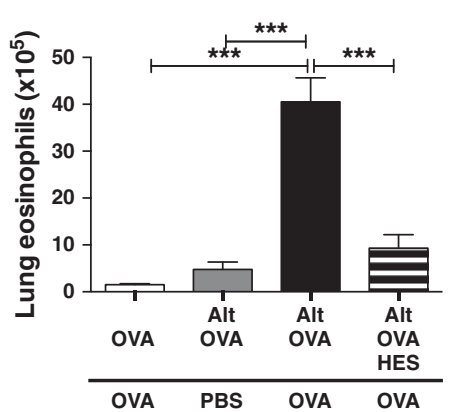

d

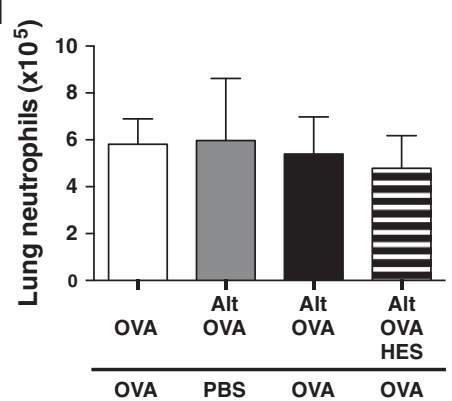

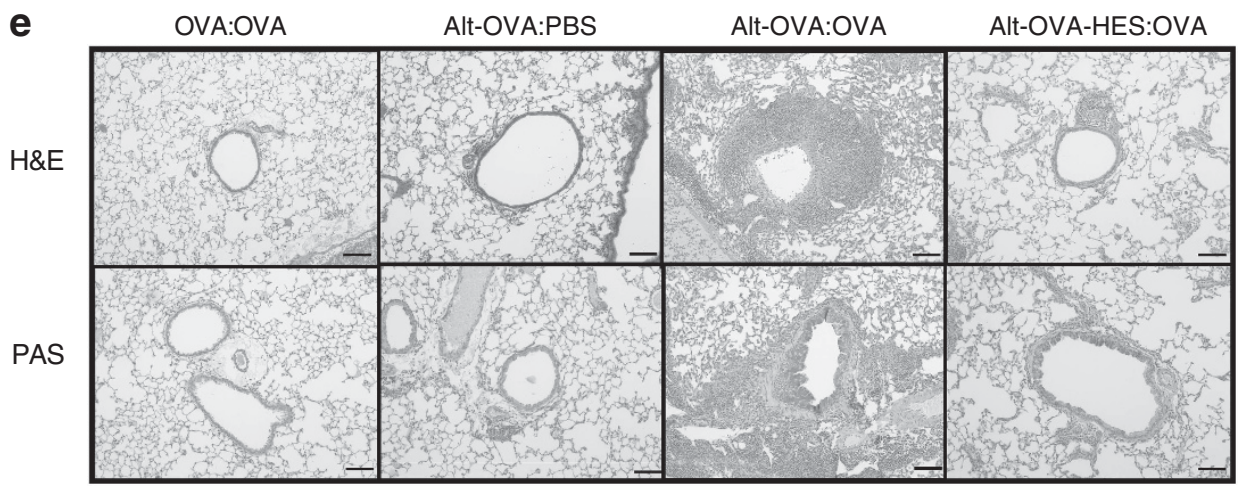

f

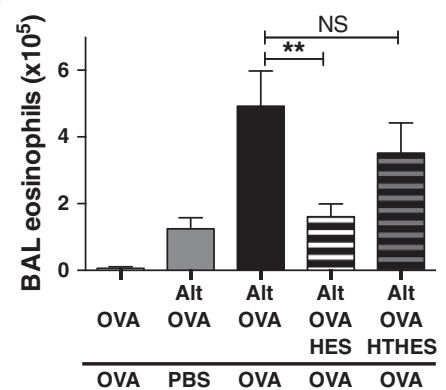

$g^{\circ}$

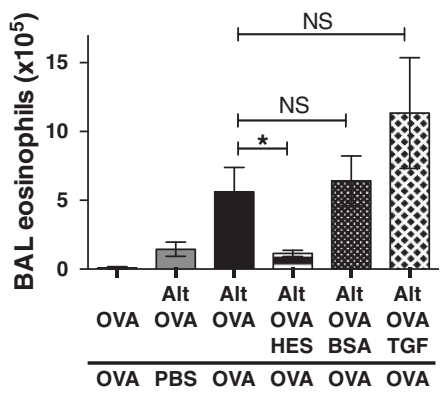

Figure 1 Alternaria-induced allergic inflammation to ovalbumin (OVA) challenge is suppressed by H. polygyrus excretory-secretory (HES) products. (a) Schematic of the Alternaria model: OVA protein $(20 \mu \mathrm{g})$ was administered to BALB/c mice intranasally, with or without $50 \mu \mathrm{g}$ Alternaria extract and $10 \mu \mathrm{g}$ HES. Two weeks later, mice were challenged by intranasal (IN) administration of $20 \mu \mathrm{g}$ OVA or phosphate-buffered saline (PBS) for 3 days, and samples

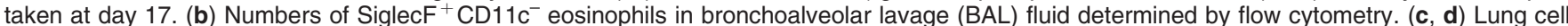
suspensions were analyzed by flow cytometry for eosinophils (as in panel b) and neutrophils (GR $1^{\text {hi }} \mathrm{CD} 11 \mathrm{~b}^{\text {hi }}$ Siglecf ${ }^{-} \mathrm{CD} 11 \mathrm{c}^{-}$). (e) Formalin-fixed lungs were sectioned and stained by Hemotoxylin and Eosin (H\&E) or Periodic Acid Schiff (PAS). Representative sections are presented, scale bar $=100 \mu \mathrm{m}$. (f) $\mathrm{HES}$ was heat treated at $95^{\circ} \mathrm{C}$ for $20 \mathrm{~min}(\mathrm{HT}-\mathrm{HES})$ before administration, and numbers of BAL SiglecF ${ }^{+} \mathrm{CD}^{-11 \mathrm{c}^{-}}$eosinophils counted. (g) BAL eosinophils from mice treated with Alternaria, OVA, and HES as described in panel a, or with $4 \mathrm{ng}$ rTGF- $\beta$ (TGF), or $10 \mu \mathrm{g}$ Bovine Serum Albumin (BSA) as indicated. Data in panels $\mathbf{b}-\mathbf{d}$ are representative of five repeat experiments, $3-5$ per mice group, in panel $\mathbf{f}$ are pooled from two repeat experiments, total $n=7$ per group, and in panel $\mathbf{g}$ are representative of two repeat experiments with four mice per group. ${ }^{\star \star \star} P<0.001$, ${ }^{\star \star} P<0.01$, ${ }^{\star} P<0.05$, and NS, not significant.

lesser degree than noted for total cytokines in the BAL (Figure 2a). We also examined the ILC compartment, defined by expression of ICOS in the absence of classical lineage markers $\left(\mathrm{ICOS}^{+}\right.$Lineage $\left.^{-}\right)$. A marked increase in the production of IL-4, as well as IL-5 and IL-13, was found within this subset in allergic mice each of which was almost completely abolished in mice that had received HES at sensitization (Figure 2d; Supplementary Figure 2). 
a

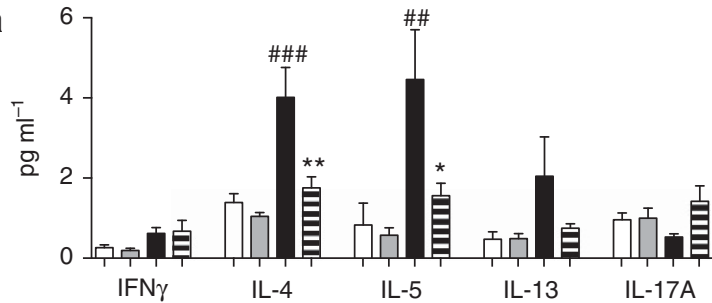

C

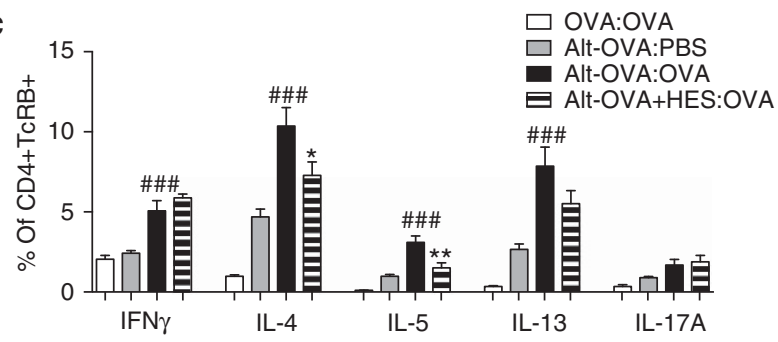

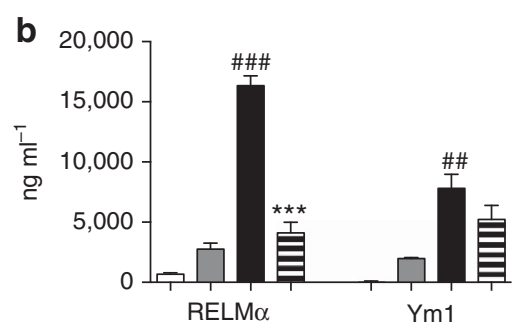

d

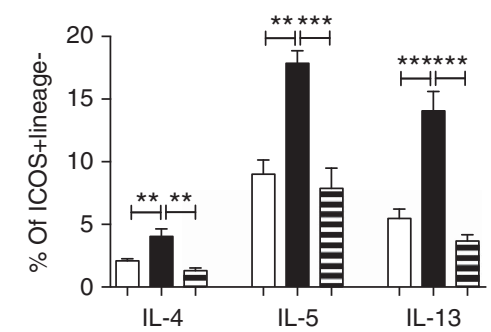

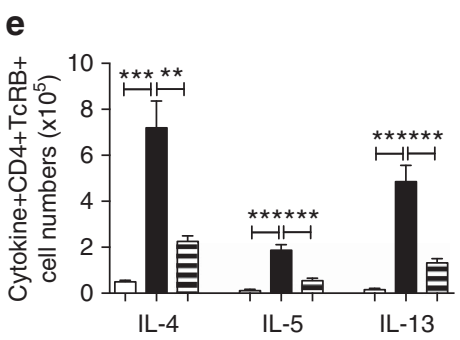
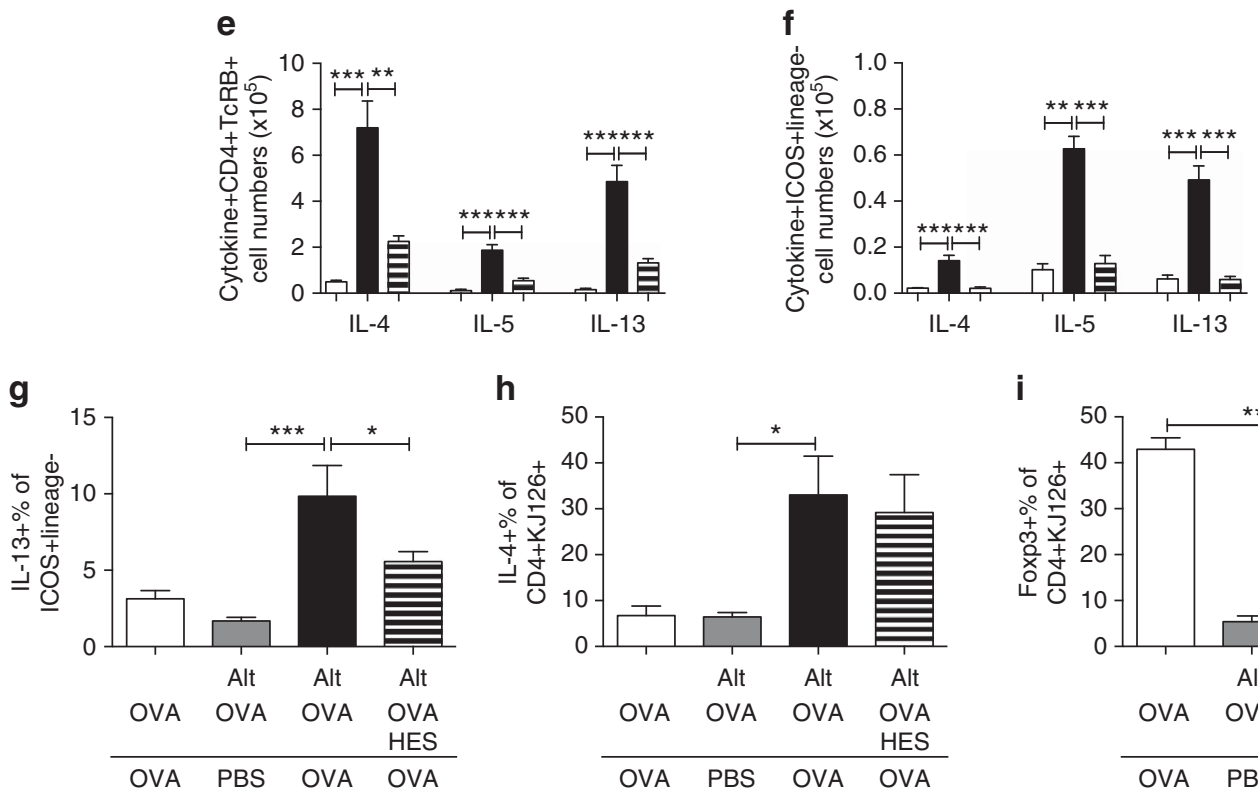

h
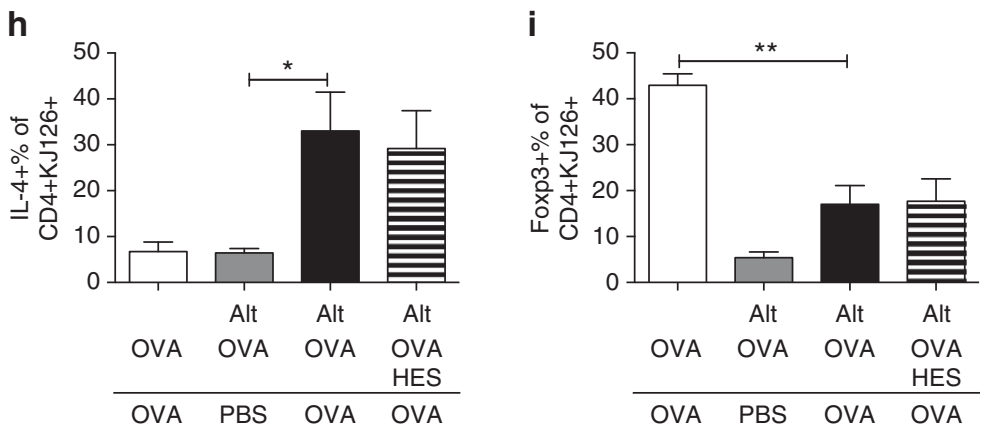

Figure 2 Suppression of innate and adaptive type 2 responsiveness by HES. Following Alternaria-OVA sensitization and challenge, BAL fluids, lungs, and draining lymph nodes were collected; in some experiments $(\mathbf{g}-\mathbf{i}), 1 \times 10^{6} \mathrm{DO} 11.10 \mathrm{OVA}$-specific T cells were transferred to mice before sensitization. Fluids were assayed for soluble cytokines and markers, and cells stained for cytokines and Foxp3. (a) Cytokines in cell-free BAL supernatant measured by cytometric bead array. (b) Type 2 myeloid cell response markers in BAL measured by ELISA. (c-f) Intracellular cytokine-positive proportions (c, d) and absolute numbers $(\mathbf{e}, \mathbf{f})$ of lung CD4 ${ }^{+} \mathrm{TCR}^{+} \mathrm{T}$ cells $(\mathbf{c}, \mathbf{e})$ and ICOS ${ }^{+}$Lineage $^{-}$innate lymphoid cells $(\mathbf{d}, \mathbf{f})$. Lung tissue cells were cultured in Phorbol Myristate Acetate (PMA)/lonomycin for $4 \mathrm{~h}$ in the presence of Brefeldin A, before staining for surface markers and intracellular cytokines. (g) Intracellular IL-13 expression by ICOS ${ }^{+}$Lineage ${ }^{-}$lung cells. (h) Intracellular IL-4 within D011.10 OVA-specific T cells from the draining lymph nodes co-staining with the clonotypic marker KJ126. (i) Intracellular Foxp3 expression in the draining lymph node CD4 ${ }^{+} \mathrm{KJ} 126^{+} \mathrm{T}$-cell population. Results are representative or pooled from at least two repeat experiments with 3-5 mice per group. Unless otherwise indicated differences are not significant. ${ }^{* \star \star} P<0.01$, ${ }^{\star \star} P<0.01$, and ${ }^{*} P<0.05$. "indicates significance when comparing Alt-OVA:PBS and Alt-OVA:OVA groups, * indicates significance when comparing Alt-OVA:OVA and Alt-OVA-HES:OVA groups in panels a-c, or as indicated by bars in panels d-j. BAL, bronchoalveolar lavage; HES, $H$. polygyrus excretory-secretory; OVA, ovalbumin; PBS, phosphate-buffered saline.

We further characterized cytokine-producing cells in the lungs of these mice by calculating absolute numbers of $\mathrm{CD} 4^{+}$ $\mathrm{T}$ cell and ILC2 cytokine-producing cells (Figure 2e,f). Both IL-4-, IL-5-, and IL-13-producing CD4 ${ }^{+} \mathrm{T}$ cells and ILC2s were dramatically reduced by HES coadministration. Although numbers of ILC2s producing IL-4, IL-5, and IL-13 in allergic mice were respectively 50 -fold, 3 -fold, and 10 -fold lower than cytokine-producing $\mathrm{CD} 4{ }^{+} \mathrm{T}$ cells, the reduction in cytokineproducing cell numbers with HES addition in ILC2s was 6.6-, 4.9-, and 8.3-fold, and in $\mathrm{CD}^{+}{ }^{+} \mathrm{T}$ cells it was only 3.2-, 3.4-, and 3.7-fold, respectively. With the known ability of ILC2s to make extremely large amounts of IL-5 and IL- $13,{ }^{35}$ they are likely to 
have a disproportionately large role in the production of these cytokines, and hence the potent suppression of ILC2s by HES could have a major impact.

\section{HES is more effective at suppressing ILC2 than OVA- specific T-cell responses}

To measure allergen-specific, rather than total, cytokine responses, we transferred OVA-specific transgenic DO11.10 $\mathrm{T}$ cells to mice before sensitization with Alternaria extract, OVA and HES. As before, we found significant decreases in lung ILC2 IL-13 production when HES was coadministered (Figure 2g). In the lung-draining lymph nodes, however, the marked increase in proportions and numbers of DO11.10 T cells expressing IL-4 in the allergic responders was unaffected by administration of HES (Figure 2h; Supplementary Figure 3), with similar results seen in lung DO11.10 cells (Supplementary Figure 3). We also examined Foxp3 expression within the transferred DO11.10 population; this was particularly high in the OVA:OVA control group that did not receive Alternaria and presumably reflects tolerance induction by soluble antigen. ${ }^{36}$ Most notably, following OVA-Alternaria priming the proportions of DO11.10 cells expressing Foxp3 were unchanged by HES administration (Figure 2i), indicating that expansion of Foxp $3^{+}$regulatory $\mathrm{T}$ cells does not readily account for the suppression of allergy in vivo.

Taken together, these data indicate that in this model HES suppresses total Th2 responses, but does not appear to suppress OVA-specific Th2 responses, while suppression of ILC2 responses is very potent. Therefore, we hypothesized that the suppression of allergic inflammation in this model by HES is more dependent on suppression of ILC2 than direct modulation of the OVA-specific T-cell compartment. Thus, we decided to investigate the role of ILC and the cytokines that induce them further.

\section{Allergic responses to Alternaria depend on MyD88 and IL-33, but not on IL-25 or TLR4 stimulation}

To ensure this model is fully dependent on an adaptive immune response to OVA, it was repeated in RAG-deficient mice, which showed no BAL or lung eosinophilic or ILC2 responses at challenge (Figure 3a,b; Supplementary Figure 4A). As ILC2s are known to be activated by IL-25 and IL-33, ${ }^{7,20}$ the course of allergic inflammation was followed in mice deficient in IL-17RB (the IL-25-specific subunit of the receptor), IL17RBxST2 (the IL-25 and IL-33 receptors), and MyD88xTRIF, as IL-33 requires MyD88-mediated signal transduction or TLR4. In IL-17RB-deficient mice, BAL and lung eosinophil (Figure 3c; Supplementary Figure 4B) and ILC2 (Figure 3d) responses were similar to those in wild-type BALB/c mice, and suppression with HES coadministration was equally profound in the presence or absence of IL-25 signaling. In contrast, IL17RBxST2-deficient mice had severely reduced BAL and lung eosinophil and ILC2 responses, and no suppression with HES administration was evident (Figure 3e,f; Supplementary Figure 4C). MyD88xTRIF-deficient mice had no detectable BAL or lung eosinophilic or ILC2 response with any treatment (Figure 3g,h; Supplementary Figure 4D). Finally,
TLR4-deficient mice showed similar levels of BAL and lung eosinophilia, and ILC2 IL-13 production (Figure 3i,j; Supplementary Figure 4E). As MyD88, but not TLR4 signaling, was found to be required for the type 2 response to Alternaria, ${ }^{37}$ and Alternaria has been reported to stimulate high levels of $\mathrm{IL}-33^{7,17}$ it is likely that the inability of MyD88xTRIF-deficient mice to respond in our model is due to the lack of IL-33 signaling. Taken together, these results indicate an important role for IL-33 (but not IL-25 or TLR4) signaling in this model.

\section{HES suppresses early innate responses to Alternaria}

Alternaria administration is known to induce ILC2 responses and eosinophil accumulation in the first days after administration, in a mechanism dependent on IL-33 signaling, before and independent of involvement of the adaptive immune system. ${ }^{7,17}$ We therefore tracked the immune response over the first $48 \mathrm{~h}$ following the in vivo exposure to Alternaria and HES. In this setting, HES coadministration completely ablated the BAL and lung eosinophil response to Alternaria (Figure 4a,b). To accurately assay ILC2 activation (in the absence of Phorbol Myristate Acetate/Ionomycin stimulation), we administered Alternaria/HES to IL-13-GFP reporter mice, and found substantial suppression by HES of the expansion of IL-13-GFP ${ }^{+}$ ILC2s at $48 \mathrm{~h}$ post administration which were lineage negative but $\mathrm{ICOS}^{+}, \mathrm{CD}_{4} 4^{+}$, and $\mathrm{CD} 25^{+}$(Figure 4c; Supplementary Figure 5). We also assessed ILC2 intracellular cytokine production over the first $48 \mathrm{~h}$ after Alternaria/HES administration and found decreased ILC2 production of IL-4, IL-5, and IL-13 (Figure 4d-f). As in the Alternaria-OVA model, when HES was heat treated, it lost its ability to suppress early eosinophilia and ILC2 IL-13 production (Figure 4g,h). To address the role of the TGF- $\beta$ mimic in HES, we again administered recombinant TGF- $\beta$, and were not able to replicate the suppressive effect of HES (Figure 4i). To discount any T-cell contribution to this effect, we repeated the exposure in RAG-deficient mice; despite the absence of adaptive lymphocytes, marked eosinophilia (Figure 4j) and ILC2 expression of IL-13 were observed at $48 \mathrm{~h}$ following Alternaria administration (Figure 4k), both of which were suppressed by HES. In addition, we were able to exclude a physical effect, such as digestion, of HES upon Alternaria extract by replicating suppression in mice given HES $6 \mathrm{~h}$ before the separate administration of Alternaria (Figure 4l).

\section{HES suppresses Alternaria-induced IL-33 release}

To capture the early events following Alternaria exposure, BAL and lung tissue samples were analyzed for cytokines and type 2 markers at 1,24, and $48 \mathrm{~h}$ post administration with and without HES (Figure 5a-d). BAL IL-5, RELM- $\alpha$, and Ym1 were all induced by $24 \mathrm{~h}$ after Alternaria administration, and these responses were all suppressed by HES coadministration (Figure $5 \mathbf{a}-\mathbf{c})$. These responses are all independent of the adaptive immune system, as they are unchanged in RAGdeficient mice (Supplementary Figure 6). IL-33 was only detectable in the BAL $1 \mathrm{~h}$ after Alternaria administration (Figure 5d) as reported previously, ${ }^{7,17}$ and was also potently suppressed by HES at this time point. Similarly to the effects 
a

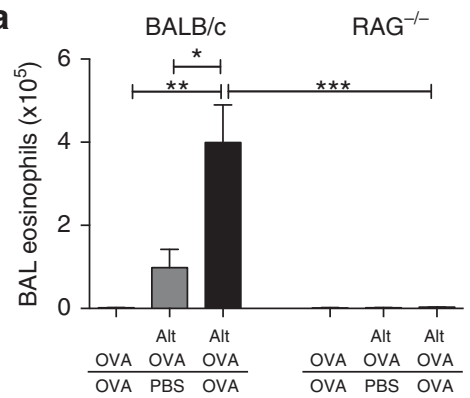

C

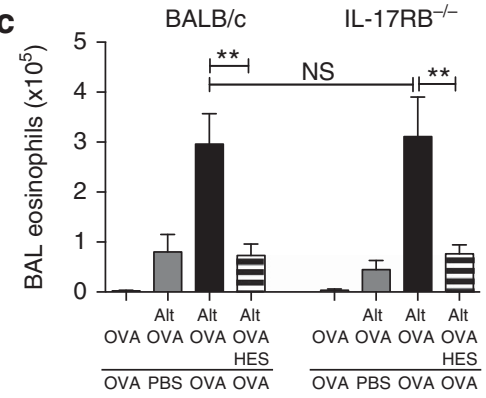

e

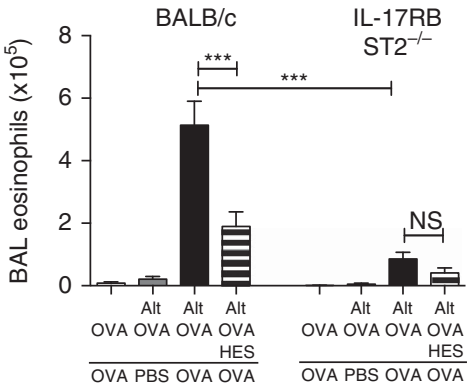

9

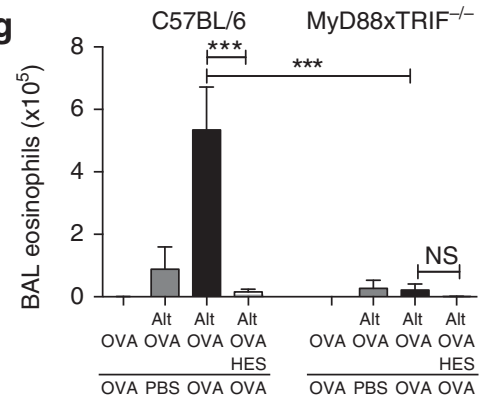

i

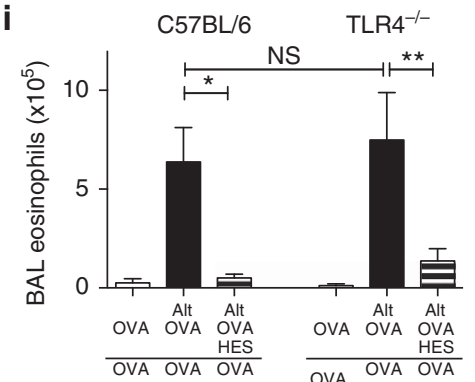

b
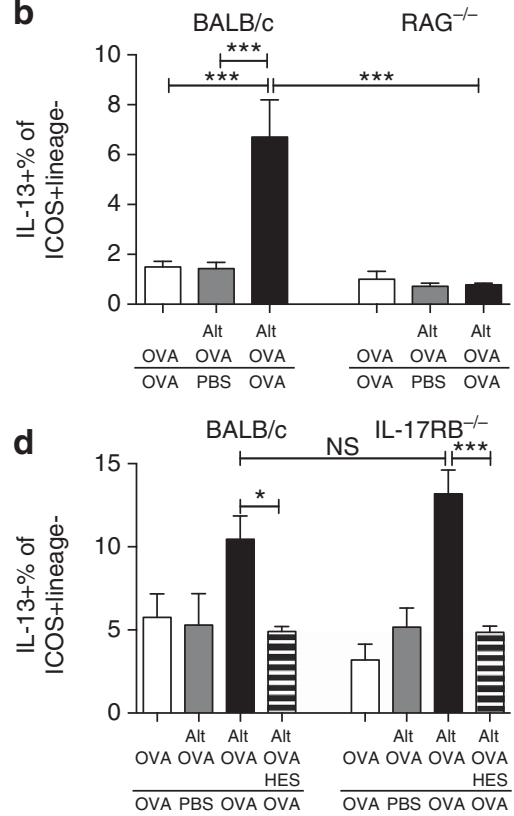

f

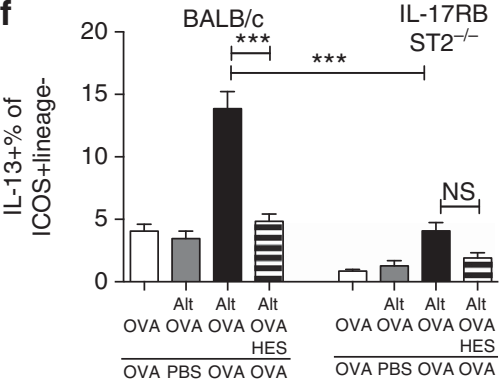

h C57BL/6 MyD88xTRIF ${ }^{-1-}$

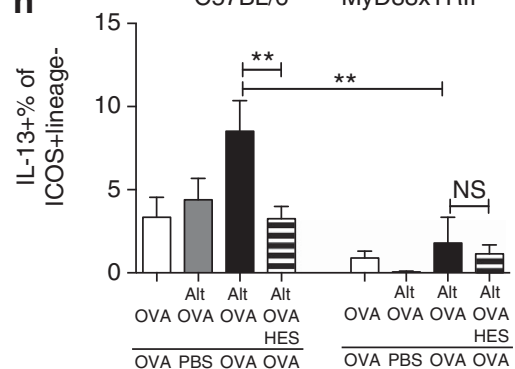

j

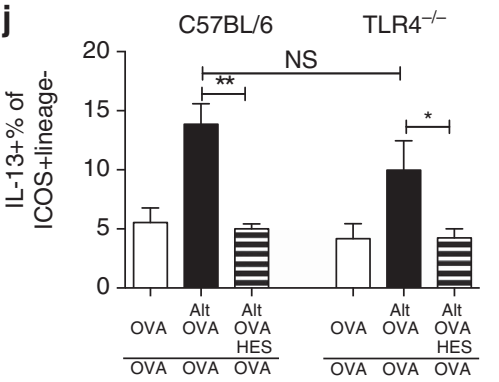

Figure 3 Alternaria-induced allergic reactivity is dependent on both innate and adaptive immune compartments in an IL-25-independent manner. The response to Alternaria-OVA administration was tested in mice deficient in recombinase-activating gene (RAG)-2 (a, b), IL-17RB (c, d), IL-17RBxST2 $(\mathbf{e}, \mathbf{f})$, MyD88xTRIF $(\mathbf{g}, \mathbf{h})$, or TLR4 $(\mathbf{i}, \mathbf{j})$ and their congenic wild-type strains; bronchoalveolar lavage (BAL) fluids were assayed for SiglecF ${ }^{+}$CD11 $^{-}$

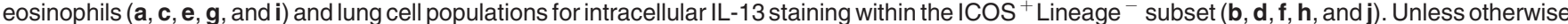
indicated differences are not significant. ${ }^{\star * \star} P<0.01,{ }^{* *} P<0.01$, and ${ }^{\star} P<0.05$. OVA, ovalbumin. 
a

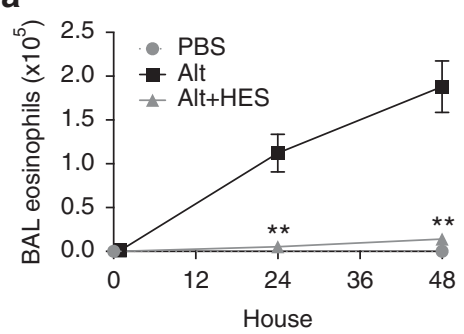

d

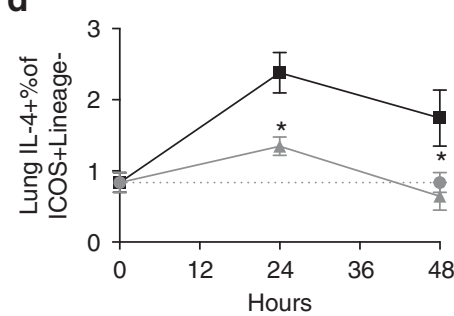

g
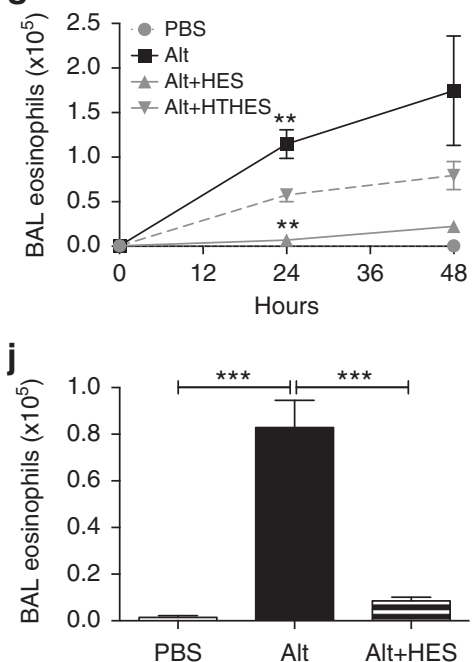

b

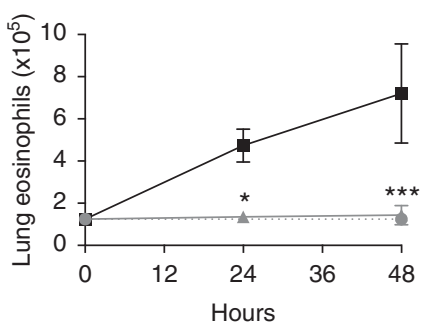

e

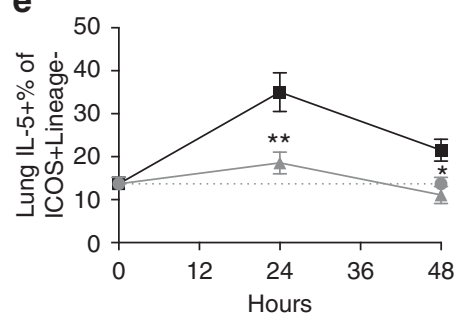

h

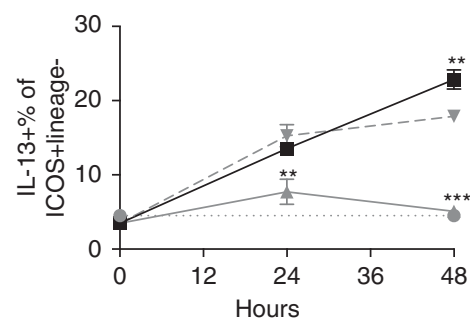

k

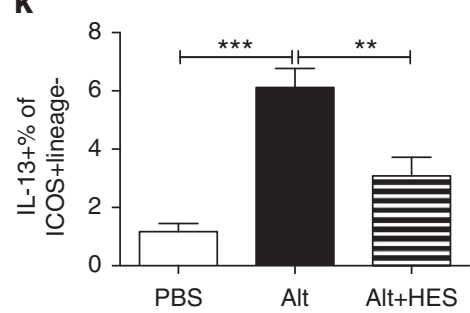

C

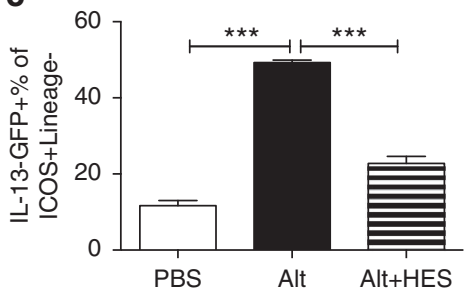

f

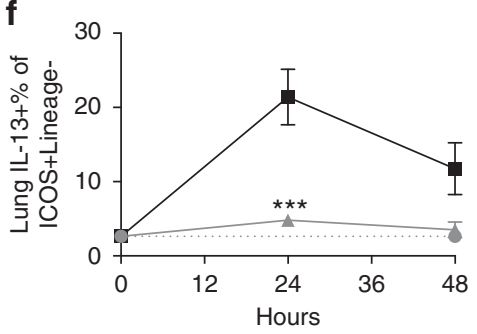

i

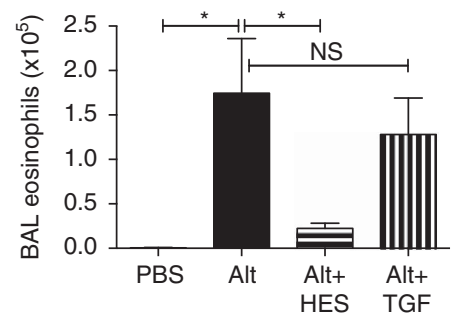

I

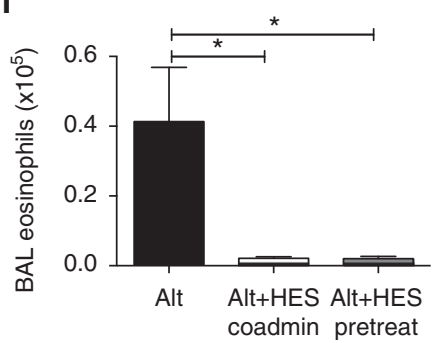

Figure 4 Alternaria induces a rapid innate eosinophilia and type 2 innate lymphoid cell (ILC2) response which is suppressed by HES. Alternaria, without OVA, was administered intranasally to BALB/c mice (a, $\mathbf{b}, \mathbf{d}-\mathbf{h}$, and I), IL-13-GFP reporter mice (c), or recombinase-activating gene (RAG)-2-deficient mice $(\mathbf{j}, \mathbf{k})$ in the presence or absence of HES, and samples harvested 24 or $48 \mathrm{~h}$ later. (a, b) Bronchoalveolar lavage (BAL) (a) and lung (b) eosinophils measured 24 and $48 \mathrm{~h}$ after administration of Alternaria with or without HES. (c) Expression of IL-13-GFP in reporter mice ${ }^{20} 48 \mathrm{~h}$ following administration of Alternaria with or without HES, measured in lung ICOS ${ }^{+}$Lineage $^{-}$cells. (d-f) Lung ICOS ${ }^{+}$Lineage $^{-}$cell expression of IL-4 (d), IL-5 (e), or IL-13 (f), measured by intracellular staining. (g, h) BAL eosinophils $(\mathbf{g})$ and intracellular IL-13 ${ }^{+}$proportion of ICOS ${ }^{+}$Lineage $^{-}$cells $(\mathbf{h})$ measured at 24 and $48 \mathrm{~h}$ following administration of Alternaria with or without HES or heat-treated HES (HT-HES). Significance shown are compared with the Alternaria $+\mathrm{HT}$-HES group (i) BALB/c mice were treated with Alternaria with or without HES or 4 ng recombinant mammalian TGF- $\beta$, and BAL eosinophils measured by flow cytometry. (j, k) BAL eosinophils (j) and IL-13 expression by innate lymphoid cell (ILCs) (k) were measured $48 \mathrm{~h}$ after administration of $A$ /ternaria with or without HES to RAG-deficient mice. (I) BAL eosinophils $48 \mathrm{~h}$ after administration of HES with, or $6 \mathrm{~h}$ before, Alternaria exposure. Results are representative or pooled from at least two repeat experiments, 3-5 mice per group. Unless otherwise indicated differences are not significant. ${ }^{* * *} P<0.01$, ${ }^{\star *} P<0.01,{ }^{*} P<0.05$. HES, $H$. polygyrus excretory-secretory; OVA, ovalbumin.

seen at later time points, the suppression of IL-33 at $1 \mathrm{~h}$ by HES was again shown to be heat labile (Figure 5e). Finally, to confirm the active production of IL-33 by live cells, we utilized IL-33-Citrine reporter mice, ${ }^{21}$ which showed upregulation of IL-33 expression in epithelial cells after Alternaria administration, and a suppression of this response with HES (Figure 5f). Suppression of IL-33 reporter expression was also evident in the Alternaria/OVA model, with a significant upregulation of IL-33-Citrine in allergic mice, and suppression when HES was coadministered with the sensitizing dose (Figure 5g; Supplementary Figure 7).

\section{Recombinant IL-33 administration abrogates HES suppression}

As the proximal event in the Alternaria-induced response appears to be IL-33 production, and that response is suppressed 

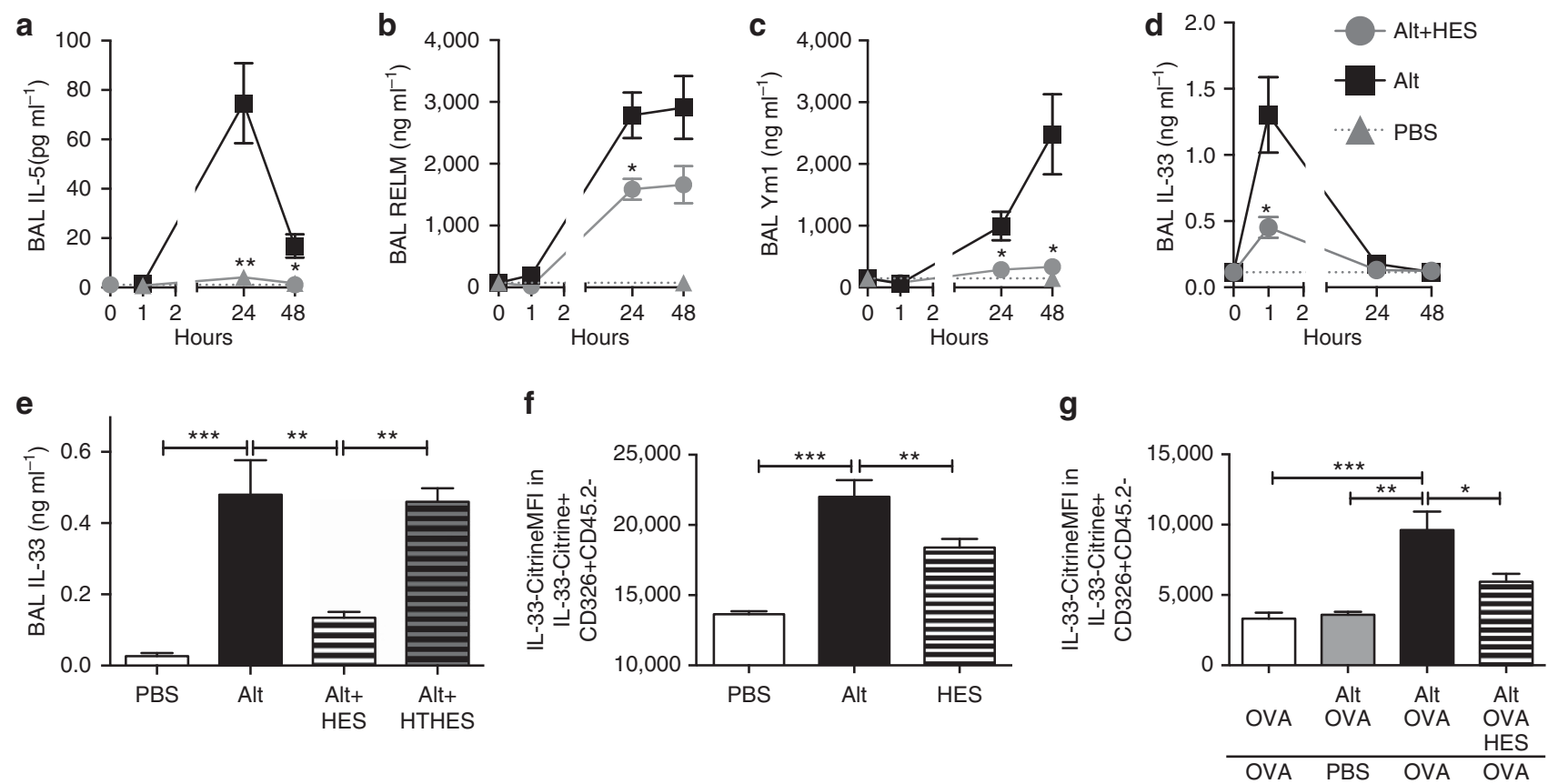

Figure 5 HES strongly suppresses early IL-33 production. (a-d) At 1, 24, and $48 \mathrm{~h}$ after Alternaria administration with or without HES, cell-free bronchoalveolar lavage (BAL) fluid was tested for levels of IL-5 (a), RELM- $\alpha$ (b), Ym1 (c), and IL-33 (d). Significance compares Alternaria level to Alternaria + HES level. (e) Alternaria, HES, and heat-treated HES (HT-HES) were administered to BALB/c mice and $1 \mathrm{~h}$ later levels of IL-33 in cell-free BAL fluid were measured. (f) Mean fluorescence intensity (MFI) of IL-33-Citrine within CD $326{ }^{+}$CD $45.2^{-}$epithelial cells $12 \mathrm{~h}$ after Alternaria $\pm \mathrm{HES}$ administration. (g) MFI of IL-33-Citrine within CD326 ${ }^{+}$CD $45.2^{-}$epithelial cells $12 \mathrm{~h}$ after the final OVA administration in the Alternaria/OVA model shown in Figure 1a. Results are pooled from two repeat experiments, $3-5$ mice per group. Unless otherwise indicated differences are not significant. ${ }^{* \star \star} P<0.01$, ${ }^{* *} P<0.01,{ }^{*} P<0.05$. HES, H. polygyrus excretory-secretory; OVA, ovalbumin.

by HES, we evaluated whether provision of exogenous IL-33 would circumvent HES suppression of downstream eosinophilia and ILCs activation. First, the short-term in vivo response to IL-33 itself in RAG-deficient mice, given in the absence of Alternaria, was tested. As shown in Figure 6a-c, although HES could slightly decrease the BAL eosinophilic response to IL-33, both lung eosinophilia and ILC2 IL-13 production were unchanged.

Finally, we investigated whether the ability of exogenous IL-33 to short-cut HES suppression also pertained to the development of the adaptive allergic response to OVA challenge in the airways. Mice were sensitized with Alternaria-OVA, with or without HES and recombinant IL-33, as shown in Figure 6d. The reduction in BAL eosinophilia with HES (Figure 6e), the Th2 response in the lung (Figure 6f), and the ILC2 $\mathrm{IL}-13^{+}$response (Figure $\mathbf{6 g}$ ) were all negated by a single administration of IL-33 at sensitization only.

\section{DISCUSSION}

The ability of helminth infections to downmodulate allergic reactivity in vivo ${ }^{31,33,38}$ has stimulated the search for molecular mechanisms of suppression that may offer new routes to prevention and treatment of allergic disease in humans. An important step toward this goal is that non-living secreted products of these parasites can recapitulate protection against allergy in vivo. ${ }^{4}$ We now show that HES, secreted by H. polygyrus, suppresses the early IL-33 to Alternaria and suppresses the later type 2 (especially ILC2) allergic response. This is the first example to our knowledge of a soluble parasite product suppressing early alarmin and ILC pathways.

Our results do not exclude pathways of suppression other than reduced IL-33 release by HES in allergic responses, in fact it seems likely that $H$. polygyrus has developed a plethora of suppressive molecules to act against type 2 immune responses at multiple levels. However, we believe the most likely mechanism of HES suppression in this model is blockade of early IL-33 release upon allergen administration, leading to a smaller early ILC2 response, and smaller allergic recall responses at later time points.

IL-33 is a pivotal alarm cytokine in infection and allergy, directly stimulating not only ILCs, ${ }^{7}$ but also macrophages, osteoclasts, Th2 cells, mast cells, DCs, and other subsets expressing T1/ST2, the IL-33 receptor. ${ }^{39}$ Downstream IL-33 elicits high levels of IL-5 and IL-13 production by IL-33stimulated ILC2s, culminating in a potent pro-allergic response that can be protective against helminth infection. Hence, the ability of helminth products to inhibit IL-33 release may have evolved to promote parasite survival, and can account for some of the anti-allergic effects of parasite infection in vivo. Indeed, IL-33 itself can promote immunity to nematodes, ${ }^{40,41}$ and IL-33-deficient mice are impaired in their expulsion of parasite species such as Nippostrongylus brasiliensis. ${ }^{20}$

HES suppressed IL-33 responses to Alternaria administration; however, the upstream mechanisms involved in IL-33 

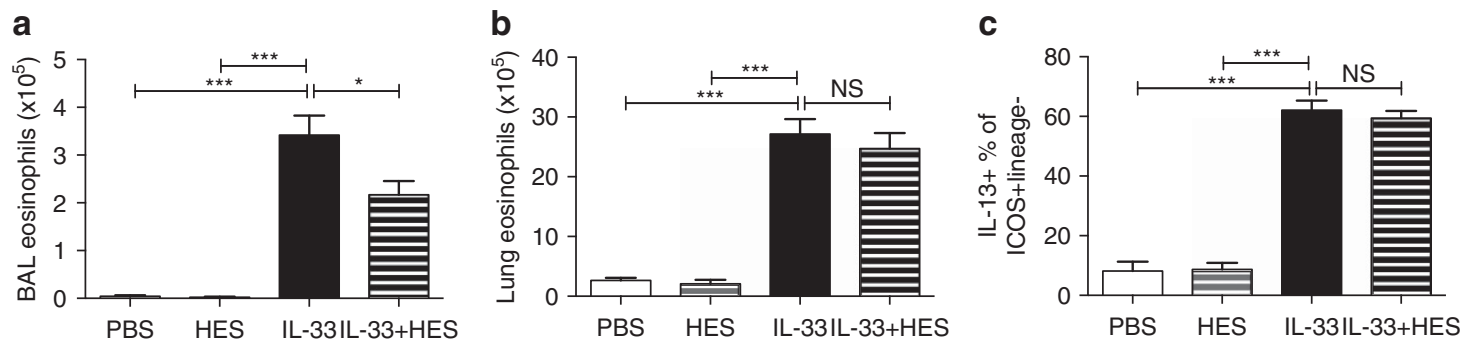

d

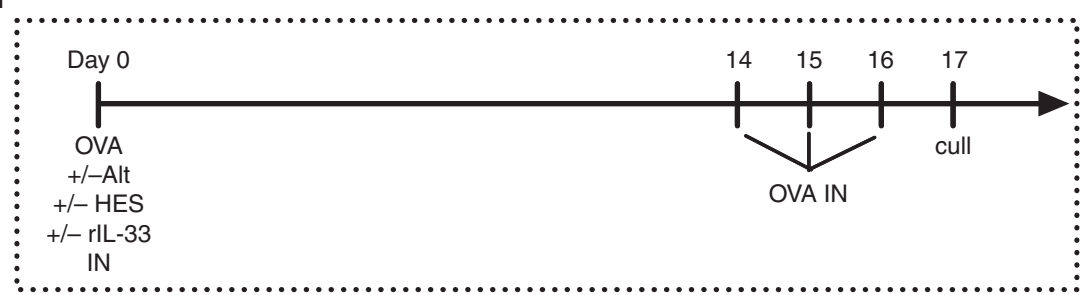

e

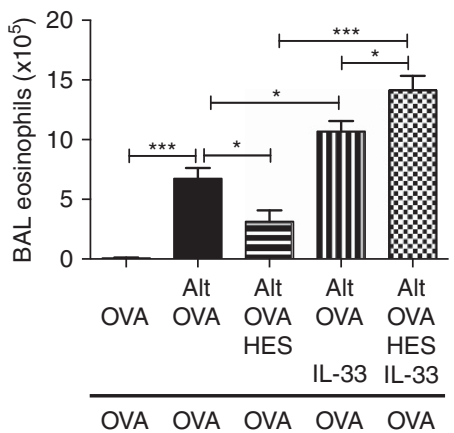

f

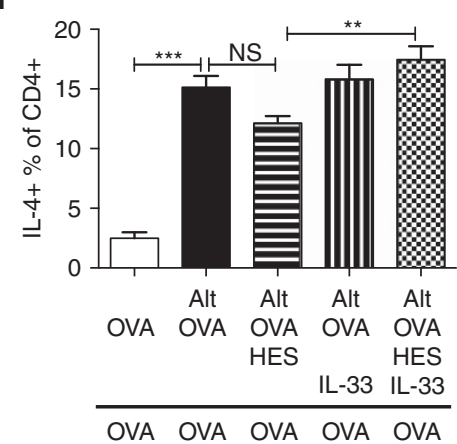

g

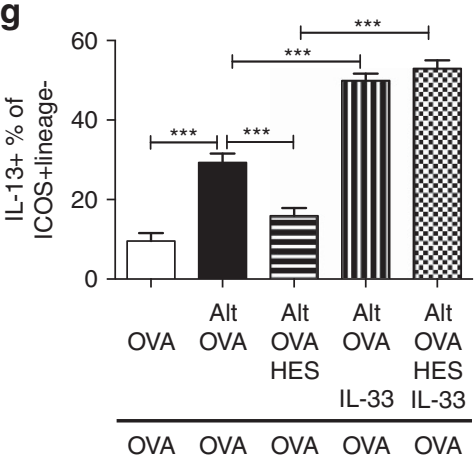

Figure 6 Exogenous IL-33 can circumvent HES-mediated suppression in vivo. (a-c) Responses in mice given recombinant IL-33 in the presence or absence of HES. Recombinase-activating gene (RAG)-2 deficient mice received $200 \mathrm{ng}$ per day IL-33 $\pm 5 \mu$ ger day HES for 3 days, and samples harvested on day 4. Numbers of bronchoalveolar lavage (BAL) (a) or lung tissue (b) eosinophils were assessed, together with lung ICOS ${ }^{+}$Lineage $^{-}$ intracellular IL-13 staining (c). (d-g) HES suppression is overridden by exogenous IL-33. Mice receiving 200 ng per mouse IL-33, Alternaria extract, OVA,

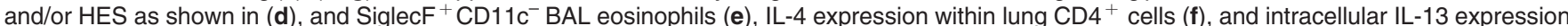
among lung ICOS ${ }^{+}$Lineage ${ }^{-}$cells $(\mathbf{g})$ were assessed. Unless otherwise indicated differences are not significant. ${ }^{* * *} P<0.01,{ }^{* *} P<0.01,{ }^{*} P<0.05$, $\mathrm{NS}=$ not significant. Results are pooled from two repeat experiments, $3-5$ mice per group. Unless otherwise indicated differences are not significant. ${ }^{\star * *} P<0.01,{ }^{\star \star} P<0.01,{ }^{\star} P<0.05$. HES, H. polygyrus excretory-secretory; OVA, ovalbumin.

release are still somewhat controversial. It is established that IL-33 does not require caspase-mediated cleavage to activate its receptor, unlike the related IL-1-family members IL-1 $\beta$ and IL-18, suggesting that it acts as an alarmin molecule, released when cells undergo necrosis. ${ }^{42}$ Indeed, rather than being converted into an active form during apoptosis, IL-33 is inactivated by caspases, ${ }^{43}$ inferring that it serves as a danger signal released under damage-induced, but not programmed, cell death. However, living cells can also release IL-33 in response to mechanical stress, ${ }^{44}$ danger signals such as ATP, ${ }^{17}$ the epithelial-derived factor Trefoil Factor $2,{ }^{45}$ and indeed IL-33 itself induces IL-33 transcription in live cells. ${ }^{21}$ Therefore, IL-33 released by dying cells may induce further IL-33 production by healthy cells.

It is possible that HES acts solely in the extracellular milieu to suppress IL-33 release, for example, by reducing levels of extracellular ATP. Several active apyrases have been identified in HES, ${ }^{46}$ which degrade ATP and ablate its ability to bind to inflammatory purinergic signaling receptors. Alternatively, as macrophage IL-33 production is suppressed by endogenous TGF- $\beta,{ }^{47}$ the TGF- $\beta$ activity of HES ${ }^{29}$ could have a similar role in this model. When we attempted to replicate the effects of HES by using recombinant mammalian TGF- $\beta$, however, we saw no effect. The possibilities remain, however, that the HES TGF- $\beta$ mimic is more efficacious in vivo and/or acts in synergy with other HES components.

An intriguing finding in the recall setting, in which Alternaria + OVA-primed mice were challenged in airways with OVA, is that ILC2 responses were found to be T cell dependent, as they were absent from RAG-deficient mice or from intact mice sham challenged with PBS after Alternarial OVA sensitization. The T-cell factor responsible for ILC2 induction is unknown, but it is tempting to speculate that $\mathrm{T}$-cell IL-2 is responsible as Alternaria-responsive lung ILC2s express the IL-2 receptor $\mathrm{CD} 25^{7}$ and IL-2 can activate ILC2s. ${ }^{48}$

The suppression of allergic responses by soluble parasite mediators has major implications for the Hygiene Hypothesis and the search for novel therapeutic agents against allergic 
disease. The suppression of initial IL-33 production has a clear effect upon ILC2 generation, and most likely impacts on activation of other innate cell types, which together enables the parasite to survive in the host. Further, these changes can help explain the observation that parasite-infected individuals have a lower probability of developing allergy and asthma. Identification of the parasite immunomodulators involved in this suppression could result in the development of novel therapeutic agents that may be used to replicate the protective effects of parasitic infection at the molecular level, resulting in new strategies for protection against allergic disease.

\section{METHODS}

Parasites and reagents. The life cycle of $H$. polygyrus bakeri was maintained, and HES products prepared, as described elsewhere. ${ }^{49}$ Class IV Ovalbumin (Sigma, Gillingham, Dorset, UK) was lipopolysaccharide (LPS) depleted by Triton X-114 phase separation, ${ }^{50}$ and the levels of LPS present in HES and depleted OVA were below 0.1 and 0.01 IU LPS per $\mu$ g protein respectively by the Limulus Amoebocyte Lysate assay (Lonza, Slough, UK). HES was heat inactivated at $95^{\circ} \mathrm{C}$ for $20 \mathrm{~min}$. A. alternata extract (Greer) was dissolved in PBS and filter sterilized. Bovine Serum Albumin (BSA) was purchased from Sigma. The carrier-free recombinant TGF- $\beta$ and IL-33 (R\&D Systems, Abingdon, UK) was dissolved in sterile PBS.

Mice. BALB/c, C57BL/6, IL-17BR-deficient, IL-17BRxST2-double deficient, MyD88xTRIF-double deficient, TLR4-deficient, RAG-2deficient, DO11.10, IL-33-Citrine, ${ }^{21}$ and IL-13-GFP ${ }^{20}$ mice were bred in-house at the University of Edinburgh and accommodated according to Home Office regulations.

Airway allergy models. In early time-point experiments, $5 \mu \mathrm{g}$ HES was administered with $50 \mu \mathrm{g}$ Alternaria extract in $50 \mu \mathrm{l}$ PBS. Mice were killed 1,24, or $48 \mathrm{~h}$ later as indicated. In the Alternaria + OVA model (see Figure 1a), $20 \mu \mathrm{g}$ LPS-depleted OVA protein, $50 \mu \mathrm{g}$ Alternaria extract, and/or $10 \mu \mathrm{g}$ HES were administered intranasally in $50 \mu \mathrm{l} \mathrm{PBS}$. Challenges of $20 \mu \mathrm{g}$ OVA protein in $50 \mu \mathrm{l}$ PBS were administered intranasally on days 14,15 , and 16 after sensitization, and mice killed on day 17. In some experiments, $20 \mu \mathrm{g}$ BSA, $200 \mathrm{ng}$ rIL-33, or $4 \mathrm{ng}$ rTGF- $\beta$ was coadministered with Alternaria extract. For DO11.10 cell transfer, single-cell suspensions of spleen and lymph-node cells were $\mathrm{CD}^{+}$purified by MACS separation (Miltenyi Biotec, Bisley, UK) according to the manufacturer's instructions. In all, $1 \times 10^{6} \mathrm{CD}^{+}$cells were transferred by intravenous injection.

Tissue preparation. At kill, bronchoalveolar cells were prepared by lavaging lungs with $500 \mu \mathrm{l}$ PBS containing 0.5\% BSA (for cytokine measurement in cell-free supernatant), followed by another three lavages to collect remaining cells. Single-cell suspensions of lung tissue were prepared by digesting the right lobes of the lung in $2 \mathrm{U} \mathrm{ml}^{-1}$ liberase TL (Roche, Burgess Hill, UK) and $80 \mathrm{U} \mathrm{ml}^{-1}$ DNase (Life Technologies, Paisley, UK) at $37^{\circ} \mathrm{C}$ with agitation for $35 \mathrm{~min}$. Draining mediastinal lymph nodes and digested lung tissue were macerated through $70 \mu \mathrm{m}$ cell strainers. For histology, lungs were inflated with, and collected into, $10 \%$ buffered formalin, incubated overnight at $4{ }^{\circ} \mathrm{C}$, then transferred to $70 \%$ ethanol, paraffin embedded and sectioned, and stained following standard protocols for Hemotoxylin and Eosin and Periodic Acid Schiff.

Flow cytometry. Cells were surface stained with fluorescently labeled antibodies to CD11c, SiglecF, Gr1, CD11b, CD4, TcR $\beta$, CD3, CD19, CD $8 \alpha$, CD49b, KJ1-26, ICOS, CD25, CD44, and ST2 or the relevant isotype controls. For intracellular Foxp3 staining, the eBioscience Foxp3 Fix/Perm kit (eBioscience, Hatfield, UK) was used. For intracellular cytokine staining, cells were stimulated for $4 \mathrm{~h}$ at $37^{\circ} \mathrm{C}$ with $500 \mathrm{ng} \mathrm{ml}^{-1}$ Phorbol Myristate Acetate, $1 \mu \mathrm{g} \mathrm{ml}^{-1}$ Ionomycin, and $10 \mu \mathrm{g} \mathrm{ml}^{-1}$ Brefeldin A (Sigma). Cells were surface stained, then permeabilized with the BD Biosciences Fixation/Permeabilisation kit (BD Biosciences, Oxford, UK) before staining for IFN- $\gamma$, IL-4, IL-5, IL-10, IL-13, and IL-17A. Live/dead Fixable Yellow or Aqua dyes (Invitrogen) were used to exclude dead cells. Samples were analyzed by flow cytometry using Becton-Dickinson FACSCanto or LSR-II flow cytometers (BD Biosciences). Cell types were characterized as: $\mathrm{CD}_{11 \mathrm{c}^{+}}$SiglecF $^{+}$(alveolar macrophages), SiglecF ${ }^{+} \mathrm{CD} 11 \mathrm{c}^{-} \mathrm{CD} 11 \mathrm{~b}^{+}$ $\mathrm{GR}^{\mathrm{lo}}$ (eosinophils), Gr1 ${ }^{\text {hi }} \mathrm{CD} 11 \mathrm{~b}^{\text {hi }} \mathrm{CD} 11 \mathrm{c}^{-}$SiglecF ${ }^{-}$(neutrophils) and $\mathrm{CD} 4{ }^{+} \mathrm{CD} 11 \mathrm{~b}{ }^{-}$( $\mathrm{T}$ helper cells). ILC2s were characterized as lineage ${ }^{-}$(CD3/CD19/CD4/CD5/CD8 $\left.\alpha / \mathrm{TcR} \beta / C D 49 b / C D 11 b / C D 11 c\right)$ and $\mathrm{ICOS}^{+}$.

ELISA. RELM- $\alpha$ and Ym- 1 were measured by ELISA, using rabbit anti-mouse RELM- $\alpha$, and biotinylated rabbit anti-mouse RELM- $\alpha$, compared with a recombinant RELM- $\alpha$ standard (Peprotech, London, UK), or the Chitinase 3-like/ECF-L (Ym1) DuoSet kit (R\&D Systems) according to the manufacturer's instructions. IL-33 was measured using the R\&D Systems ELISA kit according to the manufacturer's instructions.

Cytokine Bead Array. Cytokine levels were detected in cell-free BAL supernatant. IL-4, IL-5, IL-10, IL-13, IFN- $\gamma$, and IL-17A levels were detected using BD cytometric bead array Flex-set kits (BD Biosciences), and were acquired on a BD FACSArray.

Statistics. All data were analyzed using Prism 6 (Graphpad Prism, La Jolla, CA). Groups were analyzed by one-way ANOVA, with a Šídák's multiple comparisons post test comparing all groups with the OVA only positive control. Unless otherwise indicated differences are not significant. ${ }^{* *} P<0.001,{ }^{* *} P<0.01,{ }^{\star} P<0.05$.

SUPPLEMENTARY MATERIAL is linked to the online version of the paper at http://www.nature.com/mi

\section{ACKNOWLEDGMENTS}

We thank the American Asthma Foundation (HJMcS, NFB, RMM), the Wellcome Trust (KAS, RMM), Asthma UK (HJMcS) and the MRC (ANJMcK) for funding support, and Kara Filbey, Yvonne Harcus and Elaine Robertson for production of parasite materials and assistance with the studies presented.

\section{DISCLOSURE}

The authors declared no conflict of interest.

(c) 2014 Society for Mucosal Immunology

\section{REFERENCES}

1. Eder, W., Ege, M.J. \& von Mutius, E. The asthma epidemic. N. Engl. J. Med. 355, 2226-2235 (2006).

2. Yazdanbakhsh, M., Kremsner, P.G. \& van Ree, R. Allergy, parasites, and the hygiene hypothesis. Science 296, 490-494 (2002).

3. Fleming, J. \& Fabry, Z. The hygiene hypothesis and multiple sclerosis. Ann. Neurol. 61, 85-89 (2007).

4. McSorley, H.J. \& Maizels, R.M. Helminth infections and host immune regulation. Clin. Microbiol. Rev. 25, 585-608 (2012).

5. Fanta, C.H. Asthma. N. Engl. J. Med. 360, 1002-1014 (2009).

6. Lambrecht, B.N. \& Hammad, H. The airway epithelium in asthma. Nat. Med. 18, 684-692 (2012).

7. Bartemes, K.R., lijima, K., Kobayashi, T., Kephart, G.M., McKenzie, A.N. \& Kita, H. IL-33-responsive lineage ${ }^{-} \mathrm{CD} 25^{+} \mathrm{CD} 44^{\text {hi }}$ Iymphoid cells mediate innate type 2 immunity and allergic inflammation in the lungs. J. Immunol. 188, 1503-1513 (2012).

8. Halim, T.Y., Krauss, R.H., Sun, A.C. \& Takei, F. Lung natural helper cells are a critical source of Th2 cell-type cytokines in protease allergen-induced airway inflammation. Immunity 36, 451-463 (2012). 
9. Klein Wolterink, R.G. et al. Pulmonary innate lymphoid cells are major producers of IL-5 and IL-13 in murine models of allergic asthma. Eur. J. Immunol. 42, 1106-1116 (2012).

10. Kim, H.Y. et al. Innate lymphoid cells responding to IL-33 mediate airway hyperreactivity independently of adaptive immunity. J. Allergy Clin. Immunol. 129, 216-227. e211-216 (2012).

11. Barlow, J.L. et al. Innate IL-13-producing nuocytes arise during allergic lung inflammation and contribute to airways hyperreactivity. J. Allergy Clin. Immunol. 129, 191-198. e191-194 (2012).

12. Stern, D.A., Morgan, W.J., Halonen, M., Wright, A.L. \& Martinez, F.D. Wheezing and bronchial hyper-responsiveness in early childhood as predictors of newly diagnosed asthma in early adulthood: a longitudinal birth-cohort study. Lancet 372, 1058-1064 (2008).

13. Pulimood, T.B., Corden, J.M., Bryden, C., Sharples, L. \& Nasser, S.M. Epidemic asthma and the role of the fungal mold Alternaria alternata. J. Allergy Clin. Immunol. 120, 610-617 (2007).

14. Knutsen, A.P. et al. Fungi and allergic lower respiratory tract diseases. J. Allergy Clin. Immunol. 129, 280-291. quiz 292-283 (2012).

15. Kobayashi, T. et al. Asthma-related environmental fungus, Alternaria, activates dendritic cells and produces potent Th2 adjuvant activity. $\mathrm{J}$ Immunol 182, 2502-2510 (2009).

16. Denis, O. et al. Chronic intranasal administration of mould spores or extracts to unsensitized mice leads to lung allergic inflammation, hyperreactivity and remodelling. Immunology 122, 268-278 (2007).

17. Kouzaki, H., lijima, K., Kobayashi, T., O'Grady, S.M. \& Kita, H. The danger signal, extracellular ATP, is a sensor for an airborne allergen and triggers IL-33 release and innate Th2-type responses. J. Immunol. 186, 4375-4387 (2011).

18. Doherty, T.A. et al. STAT6 regulates natural helper cell proliferation during lung inflammation initiated by Alternaria. Am. J. Physiol. Lung Cell Mol. Physiol. 303, L577-L588 (2012).

19. Doherty, T.A. et al. Alternaria induces STAT6-dependent acute airway eosinophilia and epithelial FIZZ1 expression that promotes airway fibrosis and epithelial thickness. J. Immunol. 188, 2622-2629 (2012).

20. Neill, D.R. et al. Nuocytes represent a new innate effector leukocyte that mediates type-2 immunity. Nature 464, 1367-1370 (2010).

21. Hardman, C.S., Panova, V. \& McKenzie, A.N. IL-33 citrine reporter mice reveal the temporal and spatial expression of IL-33 during allergic lung inflammation. Eur. J. Immunol. 43, 488-498 (2013).

22. Monroy, F.G. \& Enriquez, F.J. Heligmosomoides polygyrus: a model for chronic gastrointestinal helminthiasis. Parasitol. Today $\mathbf{8}$, 49-54 (1992).

23. Finney, C.A., Taylor, M.D., Wilson, M.S. \& Maizels, R.M. Expansion and activation of $\mathrm{CD}^{+}{ }^{+} \mathrm{CD} 25^{+}$regulatory $\mathrm{T}$ cells in Heligmosomoides polygyrus infection. Eur. J. Immunol. 37, 1874-1886 (2007).

24. Rausch, S. et al. Functional analysis of effector and regulatory T cells in a parasitic nematode infection. Infect. Immun. 76, 1908-1919 (2008).

25. Wilson, M.S. et al. Helminth-induced $\mathrm{CD} 19^{+} \mathrm{CD} 23^{\text {hi }} \mathrm{B}$ cells modulate experimental allergic and autoimmune inflammation. Eur. J. Immunol. 40, 1682-1696 (2010).

26. Massacand, J.C. et al. Helminth products bypass the need for TSLP in Th2 immune responses by directly modulating dendritic cell function. Proc. Natl. Acad. Sci. USA 106, 13968-13973 (2009).

27. Smith, K.A., Hochweller, K., Hammerling, G.J., Boon, L., MacDonald, A.S. \& Maizels, R.M. Chronic helminth infection promotes immune regulation in vivo through dominance of $\mathrm{CD} 11 \mathrm{c}^{\mathrm{l}} \mathrm{CD} 103^{-}$dendritic cells. J. Immunol. 186, 7098-7109 (2011).

28. Blum, A.M. et al. Heligmosomoides polygyrus bakeri induces tolerogenic dendritic cells that block colitis and prevent antigen-specific gut $T$ cell responses. J. Immunol. 189, 2512-2520 (2012).

29. Grainger, J.R. et al. Helminth secretions induce de novo T cell Foxp3 expression and regulatory function through the TGF-beta pathway. J. Exp. Med. 207, 2331-2341 (2010).

30. Segura, M., Su, Z., Piccirillo, C. \& Stevenson, M.M. Impairment of dendritic cell function by excretory-secretory products: a potential mechanism for nematode-induced immunosuppression. Eur. J. Immunol. 37, 1887-1904 (2007).

31. McSorley, H.J., O'Gorman, M.T., Blair, N., Sutherland, T.E., Filbey, K.J. \& Maizels, R.M. Suppression of type 2 immunity and allergic airway inflammation by secreted products of the helminth Heligmosomoides polygyrus. Eur. J. Immunol. 42, 2667-2682 (2012).

32. Bortolatto, J. et al. Toll-like receptor 4 agonists adsorbed to aluminium hydroxide adjuvant attenuate ovalbumin-specific allergic airway disease: role of MyD88 adaptor molecule and interleukin-12/interferon-gamma axis. Clin. Exp. Allergy 38, 1668-1679 (2008).

33. Wilson, M.S., Taylor, M.D., Balic, A., Finney, C.A., Lamb, J.R. \& Maizels, R.M. Suppression of allergic airway inflammation by helminth-induced regulatory T cells. J. Exp. Med. 202, 1199-1212 (2005).

34. Sutherland, T.E., Maizels, R.M. \& Allen, J.E. Chitinases and chitinase-like proteins: potential therapeutic targets for the treatment of T-helper type 2 allergies. Clin. Exp. Allergy 39, 943-955 (2009).

35. Moro, $\mathrm{K}$. et al. Innate production of $\mathrm{TH} 2$ cytokines by adipose tissueassociated c-Kit ${ }^{+}$Sca- ${ }^{+}$Iymphoid cells. Nature 463, 540-544 (2010).

36. Soroosh, P. et al. Lung-resident tissue macrophages generate Foxp3 $^{+}$regulatory T cells and promote airway tolerance. J. Exp. Med. 210, 775-788 (2013)

37. Denis, O., Vincent, M., Havaux, X., De Prins, S., Treutens, G. \& Huygen, K. Induction of the specific allergic immune response is independent of proteases from the fungus Alternaria alternata. Eur. J. Immunol. 43, 907-917 (2013).

38. Bashir, M.E., Andersen, P., Fuss, I.J., Shi, H.N. \& Nagler-Anderson, C. An enteric helminth infection protects against an allergic response to dietary antigen. J. Immunol. 169, 3284-3292 (2002).

39. Liew, F.Y., Pitman, N.I. \& Mclnnes, I.B. Disease-associated functions of IL-33: the new kid in the IL-1 family. Nat. Rev. Immunol. 10, 103-110 (2010).

40. Humphreys, N.E., Xu, D., Hepworth, M.R., Liew, F.Y. \& Grencis, R.K. IL-33, a potent inducer of adaptive immunity to intestinal nematodes. J. Immunol. 180, 2443-2449 (2008).

41. Yasuda, K. et al. Contribution of IL-33-activated type II innate lymphoid cells to pulmonary eosinophilia in intestinal nematode-infected mice. Proc. Natl. Acad. Sci. USA 109, 3451-3456 (2012).

42. Nakae, S., Morita, H., Ohno, T., Arae, K., Matsumoto, K. \& Saito, H. Role of interleukin-33 in innate-type immune cells in allergy. Allergol. Int. 62, 13-20 (2013).

43. Luthi, A.U. et al. Suppression of interleukin-33 bioactivity through proteolysis by apoptotic caspases. Immunity 31, 84-98 (2009).

44. Kakkar, R., Hei, H., Dobner, S. \& Lee, R.T. Interleukin 33as a mechanically responsive cytokine secreted by living cells. J. Biol. Chem. 287, 6941-6948 (2012).

45. Wills-Karp, M. et al. Trefoil factor 2 rapidly induces interleukin 33 to promote type 2 immunity during allergic asthma and hookworm infection. J. Exp. Med. 209, 607-622 (2012).

46. Hewitson, J.P. et al. Proteomic analysis of secretory products from the model gastrointestinal nematode Heligmosomoides polygyrus reveals dominance of venom allergen-like (VAL) proteins. J. Proteomics 74, 1573-1594 (2011).

47. Rani, R., Smulian, A.G., Greaves, D.R., Hogan, S.P. \& Herbert, D.R. TGFbeta limits IL-33 production and promotes the resolution of colitis through regulation of macrophage function. Eur. J. Immunol. 41, 2000-2009 (2011).

48. Roediger, B. et al. Cutaneous immunosurveillance and regulation of inflammation by group 2 innate lymphoid cells. Nat. Immunol. 14, 564-573 (2013).

49. Harcus, Y., Nicoll, G., Murray, J., Filbey, K., Gomez-Escobar, N. \& Maizels, R.M. C-type lectins from the nematode parasites Heligmosomoides polygyrus and Nippostrongylus brasiliensis. Parasitol. Int. 58, 461-470 (2009).

50. Liu, S., Tobias, R., McClure, S., Styba, G., Shi, Q. \& Jackowski, G. Removal of endotoxin from recombinant protein preparations. Clin. Biochem. 30, 455-463 (1997).

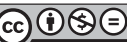

This work is licensed under the Creative Commons Attribution-NonCommercial-No Derivative Works 3.0 Unported License. To view a copy of this license, visit http:// creativecommons.org/licenses/by-nc-nd/3.0/ 